\title{
Enhancement Potential of Plant Growth-Promoting Rhizobacteria on White Beans (Phaseolus vulgaris) Seedlings
}

\author{
Kemka Ugochi ${ }^{1, a}$, Chinakwe Etienne ${ }^{1, \mathrm{~b}}$ and Egbadon Emmanuel ${ }^{1, \mathrm{c}^{*}}$ \\ ${ }^{1}$ Department of Microbiology, Federal University of Technology Owerri, Imo state, Nigeria. \\ akemkaugochi@gmail.com, beti_chukwumaeze@yahoo.com, 'emmanuelegbadon@gmail.com
}

\begin{abstract}
Keywords: Plant Growth-promoting Rhizobacteria (PGPR), White Bean (Phaseolus vulgaris), Single Inoculant
\end{abstract}

\begin{abstract}
The effect of inoculating single cultures of plant growth-promoting rhizobacteria (PGPR) on development of white beans seedling (Phaseolus vulgaris) was analyzed. Five PGPR were isolated from the rhizosphere of Okra plants and were assessed for abilities to solubilise phosphate and produce indole acetic acid (IAA). The phosphate solubilising index ranged from 6-10 while the concentration of IAA ranged from $17.48 \mathrm{mg} / 1$ to $27.43 \mathrm{mg} / \mathrm{l}$. Serratia sp. produced the highest concentration of IAA $(27.43 \mathrm{mg} / \mathrm{l})$ and had the highest solubilisation index $(10 \mathrm{~mm})$. Bacillus sp. produced the least amount of IAA (17.48mg/l) while Staphylococcus sp. had the least solubilisation index $(6 \mathrm{~mm})$. The highest percentage germination of $83.3 \%$ was observed in the seedling inoculated with Bacillus sp. The effect of PGPR on root and shoot elongation was studied hydroponically for 7 days. Significant increases $(\mathrm{P}<0.05)$ in root elongation were observed.. The highest seedling root length $(18.47 \mathrm{~cm})$ and shoot length $(19.17 \mathrm{~cm})$ were observed with inoculation of Staphylococcus sp. and Bacillus sp. respectively. The use of these bacteria as bio-inoculants could be a sustainable practice to facilitate nutrient supply to white beans seedlings.
\end{abstract}

\section{INTRODUCTION}

Plant growth promoting rhizobacteria (PGPR) are soil bacteria that aggressively colonize the rhizosphere and enhance the growth and yield of plants when applied to seeds or crops [1]. These rhizosphere bacteria enhance plant growth by different mechanisms such as solubilisation of phosphate and production of plant hormones such as Indole acetic acid [2]. The use of these bacteria with the aim of improving nutrient availability for plants is an important practice which enhances agriculture. During the past couple of decades, the use of plant growth promoting rhizobacteria for sustainable agriculture has increased tremendously in various parts of the world and they are also the trend for the future [3,2]. With increasing awareness about the possible negative effects of chemical fertilizer based agricultural practices, it is important to search for region specific microbial strains which can be used as growth promoting and enhancing inocula to achieve desired crop production [4]. Phosphorus $(\mathrm{P})$ is one of the major macronutrients needed by plants and is available in soil in insoluble forms. They are often applied to soil as chemical fertilizers in soluble inorganic forms which could be immobilized by microorganisms and so are unavailable to plants. Apart from nitrogen, phosphorous is an essential plant nutrient whose deficiency restricts crop yield severely [5]. It is generally accepted that the mechanism of mineral phosphate solubilisation by phosphate solubilisation bacteria (PSB) strains is associated with the release of low molecular weight organic acids which through their hydroxyl and carboxyl groups chelate the cations bound to phosphate, thereby converting it into soluble forms [6,7]. Microorganisms with phosphate solubilising potentials increase the availability of soluble phosphates and can also enhance plant growth by increasing the availability of trace elements such as iron, zinc etc., by production of plant growth promoting regulators [8].

However, Phosphate solubilisation is a complex phenomenon, which depends on many factors such as nutritional, physiological and growth conditions of the microbial culture [9]. It has been observed by many investigators that a high proportion of phosphate solubilising microorganisms (PSMs) especially bacteria, fungi and actinomycetes reside in the rhizosphere of plants and play an 
important role in plant nutrition as they enhance Phosphate availability to roots through converting the insoluble phosphates into soluble ions [10]. Inoculation of PSB has resulted in improving growth yield and phosphorus uptake in several crops. It is believed that production of plant growth promoting substances by PSB may contribute to their stimulatory effect on plant growth [11].

Seed or soil inoculation with PSBs is known to improve solubilisation of fixed soil phoporous and applied phosphates, resulting in higher crop yields [12].

Increasing crop yield through the use of PGPR as microbial inoculants is preferable to the use of chemical fertilizers. This is pertinent given the increased international demand for food security and environmental sustainability.

\section{MATERIALS AND METHODS}

\section{Location of study site}

This present study was carried out at the Research Farmland of the School of Agriculture and Agricultural Technology (SAAT) of The Federal University of Technology, Owerri, Imo state, Nigeria between the month of June and July 2015.

\section{Soil sampling}

Soil samples from the rhizosphere of mature okra (Abelmoschus esculentus) growing in the research farmland of the Federal University of Technology, Owerri, Imo state, Nigeria were used. The soil samples attached to the roots of the plants were collected into sterile containers after uprooting the plants. The collected samples were homogenized and transferred to the laboratory for analysis.

\section{Collection of White Bean Seedlings}

Whole white bean seeds (Phaseolus vulgaris) free from weevil infestation and other deformities were purchased from the market.

\section{Isolation of Rhizospheric bacteria from Rhizosphere of Okra seed (Abelmoschus esculentus)}

Rhizospheric bacteria were isolated from one (1) grm of the Rhizophere soil of mature Okra plant. The soil sample was serially diluted and further inoculated on Luria -Bertani (LB) agar.

\section{Screening of isolates for phosphate solubilising ability}

Isolates were screened for phosphate solubilizing ability by using modified National Botanical Research Institute Phosphate growth medium (NBRIP) [13]. Purified isolates were point inoculated on sterile NBRIP plates and incubated at room temperature for 4 days. Isolates which showed distinct zone of clearing (halozones) were selected and their solubilization indices (SI) determined.

\section{Determination of Solubilisation Index, SI}

The SI was calculated using the formula according:

$$
S I=\frac{X+Y}{X}
$$

Equation 1

Where $\mathrm{X}=$ Colony diameter

$\mathrm{Y}=$ Halozone diameter $[14]$

Estimation of Indole Acetic Acid (IAA) production by Phosphate solubilsing bacterial isolates Phosphate solubilising bacteria were screened for ability to produce indole acetic acid using the method [15]. One (1) $\mathrm{ml}$ of each of the inoculm was added separately into $2 \mathrm{mls}$ of sterile Jeon's Medium contained in $15 \mathrm{ml}$ test tubes. The test tubes were incubated for 3 days at room temperature. After incubation the tubes were centrifuged at 3000rpm for $15 \mathrm{mins}$. One (1) $\mathrm{ml}$ of each filtrate was pipetted into $15 \mathrm{ml}$ test tubes and $2 \mathrm{ml}$ of freshly prepared Salkowski reagent $\left(2 \% 0.5 \mathrm{M} \mathrm{FeCl}_{3}\right.$ in $35 \%$ perchloric acid) was added to each tube. This set up was incubated in a dark cupboard for 30mins. The appearance of a red discoloration indicated indole acetic acid (IAA) production. The amount of IAA was quantified spectroscopically at $530 \mathrm{~nm}$. The isolates which showed red discoloration were identified and used for further studies. 


\section{BIOASSAY OF SEEDLING}

Estimation of the effects of inoculation of white beans seeds by bacteria isolates was done by monitoring germination, root elongation and shoot elongation.

Disinfection of White Beans Seeds:

The seeds were disinfected by soaking them in $1 \%$ sodium hypochlorite for 5 minutes. Thereafter the seeds were washed thoroughly with sterile distilled water to remove traces of sodium hypochlorite on them.

\section{Effects of inoculants on germination of seeds:}

Six (6) disinfected seeds were placed in 7 different sterile petri dishes containing sterile cotton wool. The seeds were watered with $1 \mathrm{ml}$ of distilled water in order to moisten the sterile cotton wool to stimulate germination and incubated on a laboratory bench at room temperature $\left(28 \pm 2{ }^{\circ} \mathrm{C}\right)$. The sprouted seeds were inoculated with $100 \mu 1$ of microbial inoculants using sterile $1 \mathrm{ml}$ micropipette. The seeds were allowed to germinate.

Percentage germination was calculated thus:

$\frac{\text { Number of germinated seeds }}{\text { Number of seeds planted }} \times \frac{100}{1}$

\section{Effects of inoculation on seedling elongation:}

The influence of microbial inoculants on root and shoot elongation of the White Bean was determined daily for a period of 7 days. This was done hydroponically by growing the germinated seeds in the absence of soil as support [16]. The best sprouted seeds were suspended via a sterile millipore net over a $40 \mathrm{ml}$ beaker containing sterile water in such a manner as to allow the root gravitate towards the water (hydrotropism) and the emerging shoot gravitates towards natural sunlight (Lithotropism). This set up was placed on a laboratory bench at room temperature. The primary root and shoot elongations were measured in centimeter.

\section{Statistical Analysis:}

The data were subjected to two-way analysis of variance (two-way ANOVA) using SPSS 16.0 statistical program followed by post hoc testing. Mean values were separated using the Duncan and Student-Newman Keuls method at $\mathrm{P}=0.05$ respectively.

\section{RESULTS}

A total of five PGPR isolates were obtained. The isolates were identified as Klebsiella sp., Micrococcus sp., Staphylococcus sp., Serratia sp., and Bacillus sp.. Among PSB isolates from the rhizosphere soil samples, Serratia sp. showed best utilization of phosphate with solubilisation index of $10 \mathrm{~mm}$ and Staphylococcus sp. showed the least solubilisation of phosphate with solubilisation index of $6 \mathrm{~mm}$.

\section{Estimation of Solubilisation Index (SI)}

The ranking order of the results of the estimation of solubilisation indices by the bacterial isolates was Serratia sp. (10) >Klebsiella sp. (8.5)>Micrococcus sp.(8) >Bacillus sp. (7.5) >Staphylococcus sp. (6). All the isolates showed SI greater than 5.After 3 days of incubation, Serratia sp. showed the highest SI of $10 \mathrm{~mm}$.

Table 1: Solubilisation indices of bacterial isolates

\begin{tabular}{lc}
\hline Isolates & Solubilisation index (mm) \\
\hline Klebsiella sp. & 8.5 \\
Micrococcus sp. & 8 \\
Staphylococcus sp. & 6 \\
Serratia sp. & 10 \\
Bacillus sp. & 7.5 \\
\hline
\end{tabular}




\section{Production of Indole Acetic Acid (IAA)}

Serratia sp. produced highest amount of IAA $(27.43 \mathrm{mg} / \mathrm{l})$ while least amount of IAA $(17.48 \mathrm{mg} / \mathrm{l})$ was produced by Bacillus sp. as seen in Table 2 below. The ranking order of IAA production by the species from rhizosphere soil bacteria was Serratia sp. >Staphylococcus sp.>Micrococcus sp. $>$ Klebsiellasp. $>$ Bacillus sp.

Table 2: Estimation of Indole acetic acid production by isolates

\begin{tabular}{lc}
\hline Isolate & IAA $(\mathbf{m g} / \mathbf{l})$ \\
\hline Klebsiella sp. & $\mathbf{1 7 . 5 2}$ \\
Micrococcus sp. & $\mathbf{1 7 . 5 7}$ \\
Staphylococcus $\mathrm{sp}$. & $\mathbf{1 7 . 9 0}$ \\
Serratia sp. & $\mathbf{2 7 . 4 3}$ \\
Bacillus sp. & $\mathbf{1 7 . 4 8}$ \\
\hline
\end{tabular}

\section{Effects of inoculants on germination of seeds}

Germination was monitored for two days.

Table 3: Percentage germination of seedling treatments:

\begin{tabular}{lc}
\hline Inoculants Seedling Treatment & \% Germination \\
\hline BS + Serratia sp. & 66.7 \\
BS + Staphylococcus sp. & 66.7 \\
BS + Micrococcus sp. & 50 \\
BS + Bacillus sp. & 83.3 \\
BS + Klebsiella sp. & 50 \\
\hline
\end{tabular}

KEY: BS= Bean Seed

\section{Effect of single microbial inoculation on Root length:}

Inoculation with Staphylococcus sp. and Serratia sp. significantly increased the root length as compared to the uninoculated control. Inoculation with Klebsiella sp. and Micrococcus sp. did not result in any significant increase in root length of white beans as compared to uninoculated control.

Table 4: Root elongation of Bean seedling inoculated with single Bacterial isolates

\begin{tabular}{cccccccc}
\hline & \multicolumn{7}{c}{ TREATMENT } \\
\hline & & & Klebsiella & Micrococcus & Staphylococcus & Serratia & Bacillus \\
& Day & Control & sp. & sp. & sp. & sp. & sp. \\
Root & 1 & 0.5 & 4 & 2 & 4 & 4 & 2.5 \\
length (cm) & 2 & 1.5 & 5 & 2.5 & 6.5 & 7 & 6 \\
& 3 & 3 & 5.5 & 4 & 7 & 7.5 & 6.5 \\
& 4 & 4 & 6 & 5.5 & 8.5 & 9.5 & 8 \\
& 5 & 4.5 & 7 & 7 & 9.5 & 11 & 9.5 \\
& 6 & 6.5 & 8 & 7.5 & 11 & 12 & 12 \\
& 7 & 8 & 10 & 9.5 & 18.5 & 18 & 13.5 \\
\hline
\end{tabular}

Table 5: Shoot elongation of Bean seedling inoculated with single Bacterial isolates

\begin{tabular}{cccccccc}
\hline & \multicolumn{7}{c}{ TREATMENT } \\
\hline & Day & Control & $\begin{array}{c}\text { Klebsiella } \\
\text { sp. }\end{array}$ & $\begin{array}{c}\text { Micrococcus } \\
\text { sp. }\end{array}$ & $\begin{array}{c}\text { Stapylococcus } \\
\text { sp. }\end{array}$ & $\begin{array}{c}\text { Serratia } \\
\text { sp. }\end{array}$ & $\begin{array}{c}\text { Bacillus } \\
\text { sp. }\end{array}$ \\
\hline Shoot & 1 & 0 & 0 & 0 & 1 & 0 & 0 \\
length (cm) & 2 & 0 & 1.5 & 1 & 1.5 & 2 & 3 \\
& 3 & 2 & 3.5 & 3.5 & 2 & 3 & 5 \\
& 4 & 3 & 4 & 4.5 & 3 & 3 & 9 \\
& 5 & 4.5 & 7.5 & 6.5 & 5.5 & 5.5 & 13 \\
& 6 & 7.5 & 11 & 10.5 & 9.5 & 7 & 14.5 \\
& 7 & 9.2 & 14.5 & 12.5 & 13 & 11.5 & 20 \\
\hline
\end{tabular}




\section{Root length}

The PGPR isolates significantly $(\mathrm{P}=0.05)$ affected the root length of beans seedlings. Results reveal that root length increased in PGPR treated plants over uninoculated control. The highest root length $(18.47 \mathrm{~cm})$ was recorded in Staphylococcus $\mathrm{sp}$. which was statistically similar to Serratia sp. (18.17 $\mathrm{cm})$.

\section{Shoot length}

A significant increase in shoot length of beans seedlings was observed in response to PGPR isolates. The highest effect on shoot length was recorded in Bacillus sp. $(19.17 \mathrm{~cm})$ followed by Klebsiella sp. and Staphylococcus sp. (13.83 cm and $13.07 \mathrm{~cm})$ and also Micrococcus sp. (12.37 $\mathrm{cm})$. The lowest effect on shoot length was noted in uninoculated control $(9.27 \mathrm{~cm})$.

Table 6: Estimation of Indole acetic acid production by isolates

\begin{tabular}{llcc}
\hline \multicolumn{1}{c}{ Treatment } & N & Root length (cm) & Shoot length (cm) \\
\hline \multicolumn{1}{c}{ Single inoculation treatment } & & & \\
\hline Control & 3 & 7.5000 & 9.2667 \\
\hline Klebsiella sp. & 3 & 9.5000 & 13.8333 \\
Micrococcus sp. & 3 & 9.2000 & 12.3667 \\
Staphylococcus sp. & 3 & 18.4667 & 13.0667 \\
Serratia sp. & 3 & 18.1667 & 11.2667 \\
Bacillus sp. & 3 & 13.0000 & 19.1667 \\
\hline
\end{tabular}

\section{DISCUSSION}

In this study, plant growth-promoting rhizobacteria, Serratia sp., Bacillus sp., Staphylococcus sp., Klebsiella sp. and Micrococcus sp. were isolated from the rhizospheric soil of okra and their influence on root and shoot elongation of white beans seedlings was monitored hydroponically for seven days. Serratia sp. showed the highest solubilisation index of $10 \mathrm{~mm}$ within $72 \mathrm{hrs}$ compared to other bacterial isolates obtained. All other bacterial isolates obtained from rhizospheric soil samples were however capable of solubilizing phosphate forming clear halos. This finding is in agreement with [9] who reported that all species of phosphate solubilizing bacteria produce regulating substances and possess the ability to solubilize inorganic phosphate. In addition to phosphate solubilisation ability, another important trait of plant growth promoting rhizobacteria is production of indole acetic acid. Serratia sp. produced the highest quantity of indole acetic acid of $27.43 \mathrm{mg} / 1$. The hydroponic culture results showed that Serratia sp. achieved a percentage germination of $66.7 \%$ and achieved root elongation of $18.17 \mathrm{~cm}$. In hydroponic culture performed with Serratia $\mathrm{sp}$. SY 5 [17], its inoculation had a favourable influence on the shoot length of Zea mays and significantly increased the plant's growth. They also observed that Serratia sp. showed capacities for indole acetic acid production. Bacillus sp. showed best percentage germination ability of $83.3 \%$ and recorded a solubilisation index of $7.5 \mathrm{~mm}$ and indole acetic acid production of $17.48 \mathrm{mg} / 1$.

In a study conducted by [18] it was noted that high percentage germination observed in certain inoculated treatments could be due to plant growth activities of the bacterial species and the fact that the germinating seeds receive most of the nutrients from seed reserves and plant growth hormones such as indole acetic acid, auxins and gibberellic acid produced by the rhizobacteria which may act as stimulants.

Bacillus sp. showed highest shoot elongation measurement of $19.17 \mathrm{~cm}$. This significant influence by Bacillus sp. on germination and shoot elongation can be attributed to the fact that Bacillus sp. is relatively more versatile than others as a PGPR because of its ability to form endospores, which make them retain viability for long periods either in storage or in the soil. Bacillus subtilis resulted in emrgence of crop establishment and development of seedling vigour and also provided increase in plant growth [19]. While investigating the effect of plant growth promoting rhizobacteria on seed 
germination and plant growth of chickpea plant, it was observed that Bacillus sp., amongst others, showed significant increase in shoot and root lengths of chickpea [20].

Staphylococcus sp. recorded an indole acetic acid production of $17.90 \mathrm{mg} / 1$ when used as single treatment it achieved highest root length of $18.47 \mathrm{~cm}$ and highest shoot length of $12.67 \mathrm{~cm}$ when used in combination with Bacillus sp.

Klebsiella sp. which produced $17.52 \mathrm{mg} / 1$ of indole acetic acid showed significant effect on shoot elongation of $13.83 \mathrm{~cm}$ when applied alone.

Six strains of Klebsiella were isolated and tested for their plant growth promoting effects on moth bean seeds. The strains demonstrated favourable increase in root length of inoculated moth beans over the control [21].

\section{Conclusion and Recommendation}

This study has provided evidence to prove the capacity of certain phosphate solubilising bacterial species to enhance elongation of White Beans seedling (Phaseolus vulgaris) as well as increase its seed germination rate. Taken together, these results suggest that application of plant growth promoting rhizobacteria can induce seed germination and improve plant growth.

It is therefore recommended that these microbial inoculants especially Serratia sp., Bacillus sp. and Staphylococcus sp. be used in the production of bio-fertilizers to replace or supplement chemical fertilizers and for crop yield improvement by farmers and researchers in areas where phosphorus availability is limited or unavailable.

\section{REFERENCES}

[1] V.K. Kumar, M.S. Reddy, J.W. Kloepper, K.S. Lawrence, X.G. Zhou, D.E. Groth, S. Zhang, R.R. Sudhakara, Q. Wang, M.R.B. Raju, R. Krishnam, F.W.G. Dilantha, H. Sudini, B. Du and M.E. Miller, Commercial potential of microbial inoculants for sheath blight management and yield enhancement of rice. In: Maheshwari D.K. (ed) bacteria in agrobiology: crop ecosystems springer, Berlin pp 237-264. (2011).

[2] E. Yasar, E. Sezai, H. Ayhan and C. Ramazan, Effects of Plant growth promoting rhizobacteria on rooting and root growth of kiwifruit (Actinidia deliciosa) stem cuttings. Biol. Res.43, (2010) 91-98.

[3] M.V.B. Figueiredo, H.A. Burity, C.R. Martinez and C.P. Chanway, Plant growth-promoting rhizobacteria for improving nodulation and nitrogen fixation in the common bean (Phaseolus vulgaris L.). World J.Microbiol.Biotech.24, (2007)1187-1193.

[4] S.G. Dastager, C.K. Deepa and A. Pandey, Isolation and characterization of novel plant growth promoting rhizobacteria Micrococcus sp. N11-0909 and its interaction with cow-pea.Plant physiol. Biochem. 48(12), (2010)987-992.

[5] A. Gaume, Low phosphate tolerance of various maize cultivers; the contribution of root exudation, Ph.D. dissertation, Swiss Federal institute of Technology, Zurich, Switzerland. (2000).

[6] A.K. Kpomblekou and M.A. Tabatabai, Effect of organic acids on the release of Phosphorus from phosphate rocks. Soil Sci.158, (1994) 112-118.

[7] H. Yasmin and A. Bano, Isolation and characterization of phosphate solubilizing bacteria from rhizosphere soil of weeds of khewra salt range and attock. Pak. J. Bot.43(3), (2011) 1663-1668.

[8] P.C. Ponmurugan and C. Gopi In vitro production of growth regulators and phosphates activity by phosphate solubilising bacteria.Afr. J. Biotech.5, (2006) 348-350.

[9] Y.P. Chen, P.D. Rekha, A.B Arun, F.T. Shen, W.A. Lai and C.C. Young, Phosphate solubilizing bacteria from subtropical soil and their tricalcium phosphate solubilising abilities. App. Soil Ecol.34, (2006) 33-41.

[10] H. Antoun, Beneficial microorganisms for the sustainable use of phosphates in agriculture.Procedia Eng.46, (2012) 62-67. 
[11] B. Hameeda, O.P. Rupela, G. Reddy and K. Satyavani, Application of PRPB associated with composts and macrofauna for growth promotion of pearl millet (Pennisetum glaucum L.). Biol. Fert. Soil 43 (2), (2006)221-227.

[12] A. Kapri and L. Tewari Phosphatesolubilization potential and phosphatase activity of rhizospheric trichoderma spp.Braz. J. Microbiol. (2010)1517-8382.

[13] C.S. Nautiyal, An efficient microbiological growth medium for screening phosphorus solubilising microorganisms.FEMS Microbiol.Lett.170, (2006)2017-2021.

[14] M. Edi-Premono, M.A. Moawad and P.L.G. Vleck, Effect of phosphate solubilizing Pseudmonas putida on the growth of maize and its survival in the rhizosphere.Indonasian J. Crop Sci., 11, (1996) 13-23.

[15] J.S. Jeon, S.S. Lee, S.Y. Kim, T.S. Ahn and H.G. Song, Plant growth promotion in soil by some inoculated micro organisms. J. Microbiol. 41, (2003).271-276.

[17] S.Y. Koo and K.S. Cho, Isolation and characterization of a plant growth-promoting rhizobacterium, Serratia sp. SY 5.J. Microbiol.Biotech. 19 (11), (2009)1431-8.

[16] M. Woitke H. Junge and W.H. Schnitzler, B.subtilis as a growth parameter in hydroponically grown tomatoes under saline conditions. Acta. Hort. (ISHS) 659, (2004)363-369.

[18] N.L. Minaxi, R.C. Yadav and J. Saxena, Characterization of multifaceted Bacillus sp. RM-2 for its use as plant growth promoting bioinoculant for crops grown in semi-arid deserts.App. Soil Ecol.59, (2012)124-135.

[19] C. Custodio, F.C. Fabio, A. De Araujo, R. Manholer, F.V. De Souze and N.B. Machado-Neto, Seed treatment with Bacillus subtilis or indole Butyric Acid: germination and early development of beans seedlings. Interciencia 38 (4), (2013) 273-279.

[20] J. Yang, J.W. Klopper and C.M. Ryu, Rhizosphere bacteria help plants tolerate abiotic stress. Trends Plant Sci.14, (2009)1-4.

[21] P.S. Dhara, G.H. Chaudhari, V.M. Kasture, D.D. Dhavale and B.A. Chopade, Isolation and characterization of IAA producing Klebsiella pneumonia strains from rhizosphere of wheat (Triticum aestivum) and their effect on plant growth.Indian J. Exp. Biol.47 (12), (2009)9931000. 